\title{
Mujeres y hombres del Trabajo Social en Chile
}

\author{
Juan Elías Aspeé \\ Pontificia Universidad Católica de Valparaíso, Escuela de \\ Trabajo Social, Valparaíso, Chile (PUCV)
}

\author{
José Alejandro González Campos \\ Universidad de Playa Ancha, Facultad de Ciencias Naturales y \\ Exactas, Laboratorio Experimental de Saberes Matermáticos, \\ Valparaíso, Chile (UPLA)
}

\section{Mujeres y hombres del Trabajo Social en Chile}

Resumen: El propósito de este estudio fue analizar si el Trabajo Social sigue siendo una profesión estudiada y ejercida mayoritariamente por mujeres, y conocer cuánto avance han tenido los hombres en Trabajo Social. Para ello, se recurrió a una investigación descriptiva que detalla frecuencias absolutas y relativas del número de personas matriculadas y tituladas desde el año 2007 al 2016, en todos los niveles y tipos de instituciones en que se imparten certificaciones de trabajo social en Chile. El estudio concluye que el $81 \%$ de estudiantes de Trabajo Social (técnico y profesional) fueron mujeres y que el 19\% fueron hombres, proporción que se replica cercanamente en las titulaciones, hecho que acentúa la distancia entre sexos. El Trabajo Social fue, es, y según los datos, seguirá siendo eminentemente ejercida y estudiada por mujeres, concentrado en institutos profesionales, privado y tecnificado.

Palabras clave: Feminización. Masculinización. Educación superior. Chile. Trabajo Social. Mercado académico.

\section{Mulheres e homens do Serviço Social no Chile}

Resumo: O propósito deste estudo foi analisar se o Serviço Social continua sendo uma profissão estudada e exercida majoritariamente por mulheres, e conhecer o quanto os homens têm avançado neste campo. Para isso, foi realizada uma pesquisa descritiva que detalha frequências absolutas e relativas do número de pessoas matriculadas e graduadas desde 2007 a 2016, em todos os níveis e tipos de instituições em que são emitidas certificações de Serviço Social no Chile. O estudo conclui que $81 \%$ dos estudantes de Serviço Social (técnico e profissional) foram mulheres e que $19 \%$ foram homens, proporção que se repete aproximadamente entre os graduados, fato que acentua a distância entre os sexos. O Serviço Social foi, é, e, segundo os dados, continuará sendo exercido e estudado predominantemente por mulheres, concentrado em institutos profissionais, privados e técnicos.

Palavras-chave: Feminilização. Masculinização. Educação superior. Chile. Serviço Social. Mercado Acadêmico.

\section{Women and Men in Social Work in Chile}

Abstract: The purpose of this study was to analyze if Social Work continues to be a profession studied and exercised predominantly by women, and to know how much men have advanced in the field. It uses a descriptive investigation that details absolute and relative frequencies of the number of people registered and graduated from 2007 until 2016, at all levels and types of institutions that issue certifications to social workers in Chile. The study concludes that $81 \%$ of Social Work students (at the technical and professional levels) were women and that $19 \%$ were men, a proportion that is repeated closely among the graduates, a fact that emphasizes the distance between the sexes. Social work was, is - and according to the data, will continue to be - predominantly exercised and studied by women, who are the vast majority in the private and technical professional institutions.

Keywords: Feminization. Masculinization. Higher Education. Chile. Social Work. Academic Market.

Recibido en 24.04.2017. Aprobado en 05.09.2017. Revisado en 08.12.2017.

(C) El(Los) Autor(es). 2018 Acceso Abierto Esta obra está licenciada bajo los términos de la Licencia Creative (cc) CY Commons Atribución-NoComercial 4.0 Internacional (https://creativecommons.org/licenses/by-nc/4.0/
deed.es), que permite copiar, distribuir y reproducir en cualquier medio, así como también adaptar, transformar y crear a partir de este material, desde que para fines no comerciales, y que usted fornezca el crédito debido a los autores y a la fuente, insiera un enlace para la Licencia Creative Commons e indique si fueron hechas alteraciones. 


\section{Introducción}

Los cambios en los sistemas de producción y las guerras mundiales generadas por hombres y sus problemas sociales derivados, condesados en la llamada cuestión social, fueron atendidos, compensados y muchas veces superados por mujeres. Mary Richmond es el epítome de la forma en como las mujeres tomaron la atención de la cuestión social y cristalizaron profesionalizadamente un conjunto de tradiciones filantrópicas y caritativas. El trabajo social como disciplina y profesión nace femenino, para atender los problemas que la masculinidad dominante generó. No por la maldad intrínseca de los hombres y/o por la bondad intrínseca de las mujeres, sino por la división social de roles generada con base al sexo (BOURDIEU, 2005), que en dicha época tenían un peso mayor que el actual (finales del siglo 19 y principios del siglo 20).

La división sexual de trabajo (BOURDIEU, 2005) y la concepción entre lo público y lo privado (TOURAINE, 2007) marcaron la identidad femenina del trabajo social desde sus inicios, en la medida que la atención a los problemas familiares, concebidos como parte del mundo privado, se entendía como una función de las mujeres ajenas a lo público y lo político, que era atendido por los hombres. El punto es que esta feminización marca la identidad del trabajo social desde su inicio y la acompaña hasta el día de hoy.

Para Bañez (1997), el trabajo social es una profesión mayoritariamente por mujeres, pues las funciones que se le atribuyen requieren de habilidades consideradas femeninas, asociadas al control de la vida cotidiana (domésticas). Esta concentración de mujeres en el trabajo social, puede ser entidad como la aceptación de la ideología del amor por parte de las mujeres, concretada en una profesión (GRASSI, 1989).

En Chile, Vidal (2009a) en un estudio de seguimiento de las y los egresados de trabajo social de la Universidad Católica Silva Henríquez, determinó que el $80 \%$ son mujeres y el 20\% son hombres, lo que coindice con las cifras a nivel nacional en dicho año. La misma autora, en otro estudio determinó que de un universo de 307 profesionales, el $89 \%$ fueron mujeres y el 11\% fueron hombres, cifras que no se distancian significativamente de investigaciones anteriores, nacionales e internacionales (VIDAL, 2009b). Estas cifras son reafirmadas por Castañeda y Salamé (2014), quienes establecieron que el $80 \%$ de estudiantes universitarios que ingresaron a primer año de trabajo social, entre los años 2010 al 2014, fueron mujeres.

Esta preeminencia femenina en el trabajo social, genera nodos críticos tanto a mujeres como a hombres que deciden estudiar y luego ejercer esta profesión. En las mujeres esta situación genera exclusión de determinados cargos y funciones que se consideran masculinas (VIDAL, 2009c). Ello es reflejo de una barrera invisible que impide a las mujeres acceder a cargos de mayor responsabilidad (LUCI, 2010), y en condiciones de precariedad laboral (VIDAL, 2009a). En tanto, en los hombres esta situación genera un conflicto entre su rol profesional (feminizando) y su comportamiento social aceptado, ya que los hombres que ejercen el trabajo social lo hacen desde un comportamiento cultural masculino hegemónico, por lo cual su identidad profesional entra en conflicto con su identidad personal y social (VALENZUELA, 2014).

En el año 2014, Aspeé realizó un estudio acerca del mercado laboral y académico del trabajo social en Chile, cuyos principales resultados indicaron que dicho mercado está copado, con baja empleabilidad y bajas remuneraciones, debido a la gran cantidad de instituciones y programas que ofrecen certificaciones en trabajo social, concentradas en institutos profesionales, organismos que han acaparado las cifras de vacantes, programas y personas tituladas de esta área, en desmedro del desarrollo universitario de la disciplina. A dicha situación, Aspeé (2014) la denominó instipetización del trabajo social, y aunque no se refirió a su expresión según sexo, si es un precedente de la presente investigación, en la medida que indica que la concentración de matrículas y titulaciones debería sucederse en este tipo de instituciones, con independencia de dicha variable. Es decir, se esperaría que mujeres y hombres concentren su matrícula y titulación en institutos profesionales y no en universidades. Ello pese a que el trabajo social o servicio social debería ser exclusivamente universitario ${ }^{1}$.

Ahora bien, estudiar el fenómeno de la feminización y/o la masculinización del trabajo social es básico para poder resolver la duda de Grassi planteada ya en 1989, que cuestionaba la función objetiva de la profesión del trabajo social como un extensión internalizada de la naturaleza femenina, subjetivamente aceptada por las mujeres. Esta duda, es relevante si los datos indican una preeminencia de mujeres, hecho que en ningún caso debe darse por sentado. Más bien, deben ser los datos los que ratifiquen o desmientan dicha realidad y luego permitan ahondar en la misma. Por ello, y dentro del contexto descrito, nace la necesidad de realizar un análisis longitudinal de la matrícula y titulación de hombres y mujeres en trabajo social, de manera de conocer si esta preeminencia femenina se mantiene en el tiempo, ha aumentado o ha disminuido. Por consiguiente, esta investigación muestra también cómo ha evolucionado la participación de hombres en trabajo social en Chile. Además, esta preocupación se enmarca dentro de un sistema de educación superior altamente diverso y mercantilizado (CARMONA-LÓPEZ; TORO-JARAMILLO; RIASCOS-GONZALES, 2014; OLIVA, 2008), del que forman parte más de un millón doscientas mil personas, distribuidas en más de 
160 instituciones. Por ende, al mismo tiempo, esta investigación pretende conocer cómo se distribuyen las cifras de matrículas y titulaciones por sexo, según el nivel de estudios y el tipo de institución de educación superior en que se ofrecen certificaciones en trabajo social, visualizando los posibles efectos de estas características estructurales en el trabajo social.

Para organizar el texto y de manera que sea auto-contenido, luego de esta introducción se presenta un apéndice metodológico, donde se describe el diseño general de la investigación, en seguida se exponen los resultados más trascendentes en función de matrículas, titulaciones y tasas pertinentes, para luego finalizar con las conclusiones y derivaciones que son posibles de establecer, con base a la referencia teórica y empírica tratada.

\section{Método}

El presente texto expone los resultados de una investigación cuantitativa no experimental de tipo descriptiva, que se basó en el análisis de fuentes secundarias de información, para caracterizar las matrículas y titulaciones entre los años 2007 al año 2015, según sexo. El propósito fundamental de la investigación fue determinar las diferencias según sexo en la composición de estudiantes y titulados de trabajo social en todos los niveles y tipos de instituciones de educación superior en Chile. Para ello, se recurrió al escudriñamiento de las bases públicas del Servicio de Información de Educación Superior (SIES) del Ministerio de Educación de Chile:

- Base Matrícula Histórica 2007-2015, actualizada al 26/08/2015 (SIES, 2016a).

- Base Titulados Histórica 2007-2014, actualizada al 26/08/2015 (SIES, 2016b).

En todas las bases indicadas, el análisis se concentró en las áreas de carrera genérica (o área carrera de futuro laboral) trabajo social y técnico en servicio social ${ }^{2}$. Por consiguiente, y de aquí en adelante, cuando se hable de trabajo social se referirá al nivel profesional (que incluye programas otorgados en Universidades, que otorgan licenciatura en el área y en Institutos profesionales, que no otorgan licenciatura en la misma) y cuando se hable de técnico en servicio social, se referirá justamente al nivel de técnico. De esta manera, la investigación es censal, no probabilística, ya que se utiliza el $100 \%$ de los datos contenidos en las bases indicadas precedentemente.

\section{Resultados}

\section{Matrícula total}

Desde el año 2007 al año 2015 han estudiado trabajo social en cualquiera de sus niveles (técnico y profesional) y en cualquiera de sus nomenclaturas (servicio social o trabajo social ${ }^{3}$ ) y en todos los tipos de instituciones de educación superior existentes en Chile, 234.083 personas. De dicho total, 189.874 fueron mujeres y 44.209 fueron hombres, es decir, una proporción de 1 hombre por cada 5,3 mujeres. Tanto en hombres como en mujeres, la mayor parte de la matrícula se sucedió en institutos profesionales (IP) con 92.796 mujeres y 21.747 hombres en dichas instituciones.

Tanto en mujeres como en hombres existió un aumento en la matrícula de trabajo social desde el año 2007 al 2015. Las mujeres pasaron de 12.956 personas a 19.545 personas, mientras que los hombres que ingresaron al nivel profesional en trabajo social saltaron de 2.709 personas a 5.039. En términos proporcionales, existe un $81 \%$ de mujeres versus un $19 \%$ de hombres en el periodo analizado, aunque en el año 2007 esta proporción fue de $83 \%$ de mujeres versus un $17 \%$ de hombres.

En el nivel técnico también existió una predominancia de las mujeres por sobre los hombres (en términos absolutos), quienes alcanzaron 5.066 personas entre 2007 al 2015, mientras que los hombres alcanzaron la cifra de 1.072 personas en el mismo periodo de tiempo. En términos proporcionales, en este nivel y periodo de tiempo, el $18 \%$ fueron hombres y el $82 \%$ fueron mujeres.

En el Gráfico 1 se observa una notoria preponderancia de la matrícula de hombres en IP en trabajo social, seguido de la matrícula en trabajo social en universidades privadas (UP), y en tercer lugar la matrícula en técnico en servicio social en IP. Asimismo, se advierte un descenso paulatino en el número de hombres matriculados en instituciones del Consejo de Rectores de las Universidades Chilenas ${ }^{4}$ (UC) y un lento, pero creciente número de matriculados en técnico en servicio social de centros de formación técnica (CFT). Desde 2007 el mayor crecimiento porcentual se sucedió en la matrícula de hombres en técnico en servicio social en IP, matrícula que acumuló hasta el año 2015 , un $657 \%$ de alza. Por su parte, la menor acumulación porcentual se la adjudicó la matrícula de trabajo social en UC, con un $2 \%$ de aumento. 
Gráfico 1 - Matrícula total de hombres, según nivel e institución

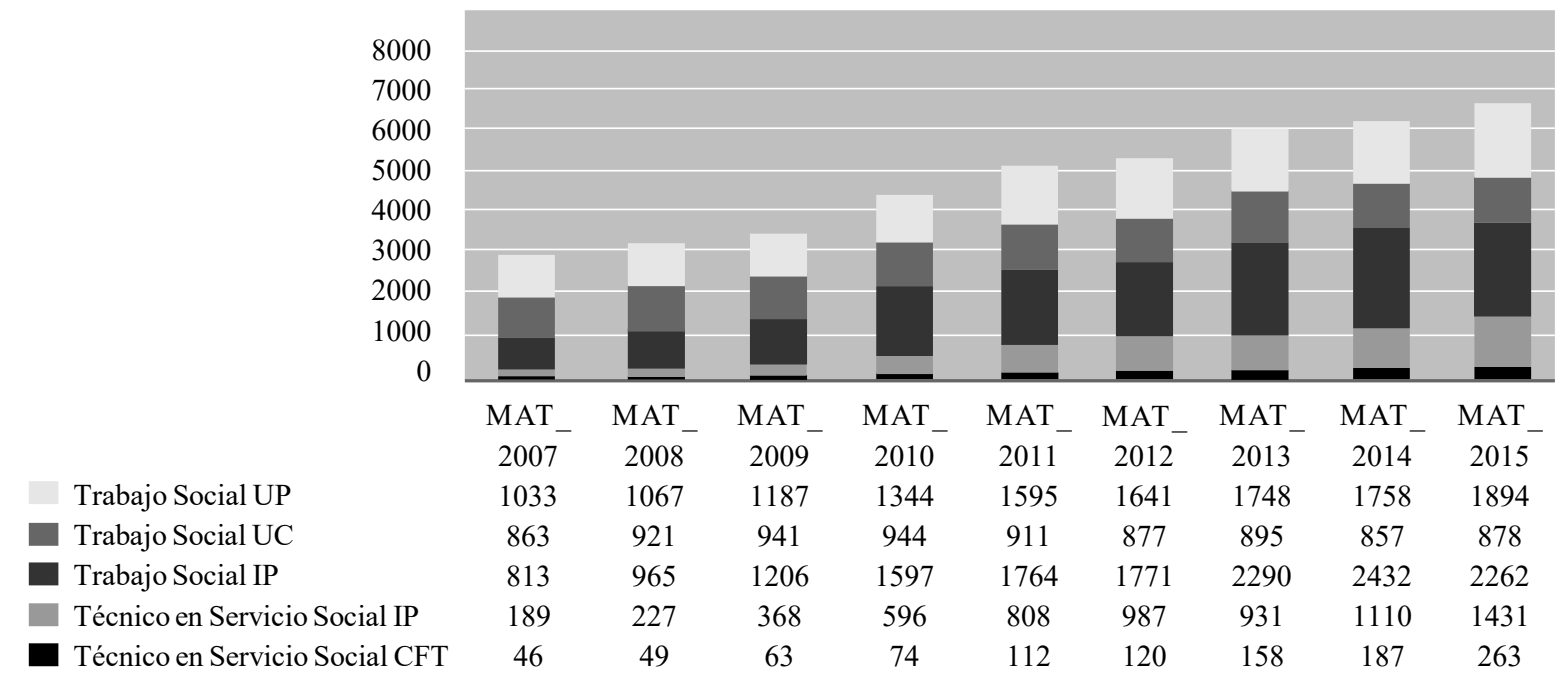

Se eliminó el nivel técnico en Servicio Social en UP, ya que desde 2009 no hay matrículas.

Fuente: elaboración propia, con datos SIES(2016a).

En el Gráfico 2 se observa que las tendencias descritas para los hombres son extrapolables a la evolución de la matrícula en mujeres. Es decir, que el mayor aumento absoluto se sucede en trabajo social en IP, seguido por trabajo social en UP, y en tercer lugar por la matrícula en técnico en servicio social en IP. Consecuentemente, la matrícula en trabajo social UC ha experimentado una merma en el tiempo y aparece una significativa matrícula de técnico en servicio social en CFT. Asimismo, el mayor porcentaje acumulado de la evolución de la matrícula en mujeres desde 2007 al 2015, ocurre en el nivel de técnico en servicio social de IP, con un 805\% de aumento. Notorio es el caso de la evolución porcentual de la matrícula de trabajo social en UC, pues a lo largo del periodo desciende en un $20 \%$.

\section{Gráfico 2 - Matrícula total de mujeres, según nivel e institución}

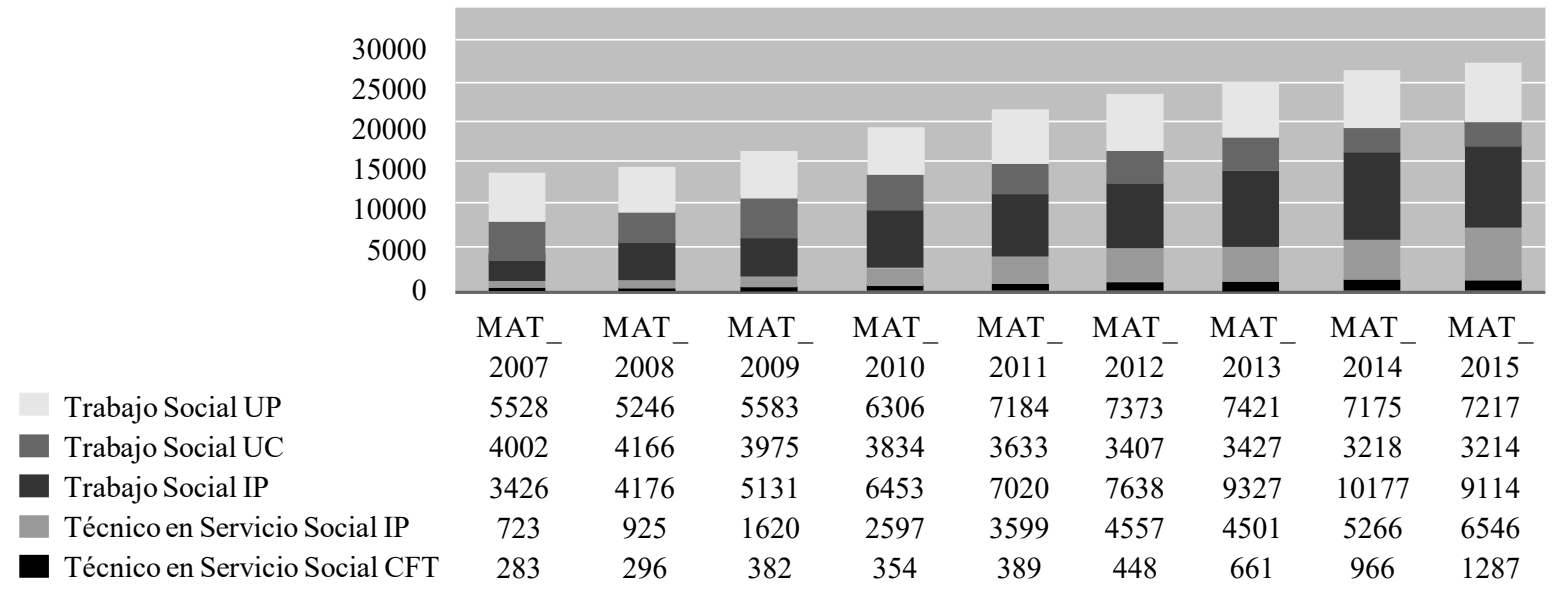

Se eliminó en nivel técnico en servicio social en UP, ya que desde 2009 no hay matriculadas.

Fuente: elaboración propia, con datos SIES(2016a).

\section{Matrícula primer año}

Los ingresos de hombres de primer año sumaron 15.294 estudiantes, mientras que los ingresos de primer año en mujeres sumaron 60.277 estudiantes, es decir, una proporción de $20 \%$ de hombres y de $80 \%$ de mujeres. 
Además, la matrícula de hombres de primer año ha acumulado un aumento del 68\% de 2007 al 2015 (sobre si mismos), mientras que las mujeres en el mismo periodo de tiempo ha experimentado un $53 \%$ de alza (sobre si mismas). En conjunto, la matrícula de primer año en trabajo social y técnico en servicio social ha aumentado en un 55\%, desde el año 2007 al año 2015.

También se observó, respecto de los hombres, una sostenida alza en la matrícula de primer año en el nivel técnico en servicio social de IP y en el nivel de trabajo social en UP (ver Gráfico 3). Asimismo, se visualiza un descenso desde el año 2014 al año 2015 de la matrícula de trabajo social en IP, y una relativa estabilidad en la matrícula en trabajo social de UC. De los 15.294 estudiantes que han ingresado a primer año entre 2007 y 2015, el 34\% ingresó a trabajo social en IP, el 23\% a técnico en servicio social en IP y sólo el 12\% a UC.

\section{Gráfico 3 - Evolución de la matrícula de hombres en primer año, según nivel y tipo de institución}

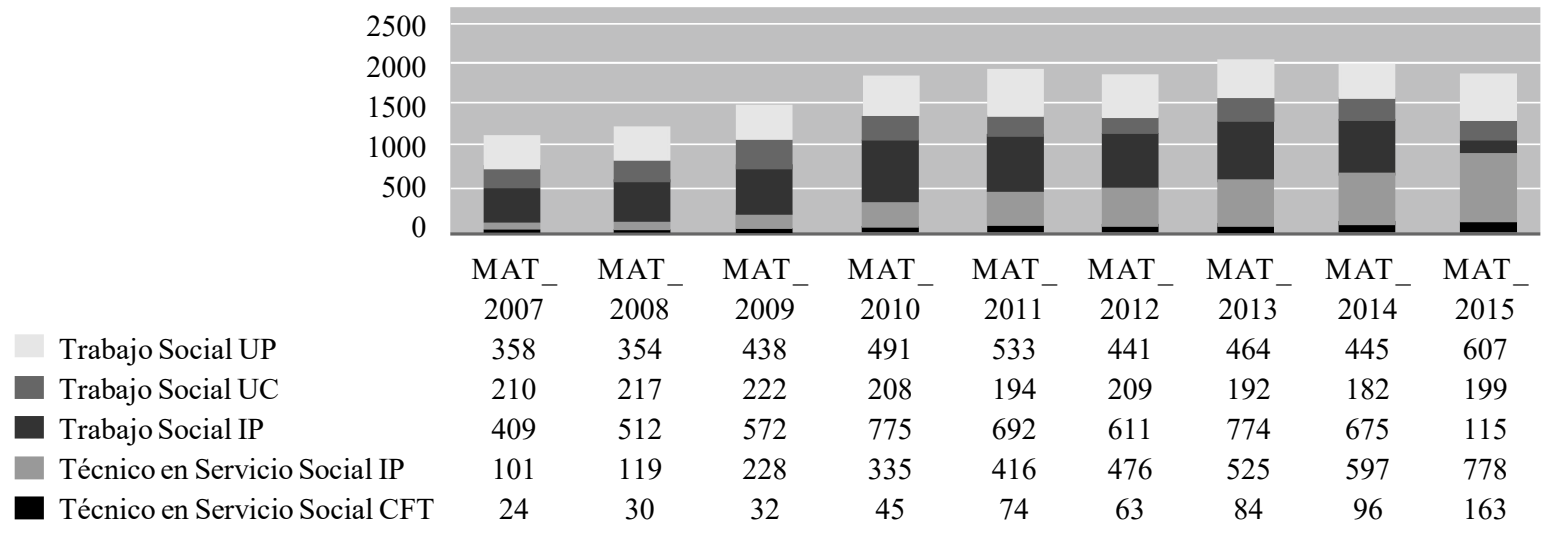

Se eliminó técnico en servicio social en UP, pues desde 2008 no hay ingresos.

Fuente: elaboración propia, con datos SIES (2016a).

\section{Gráfico 4 - Evolución de la matrícula de mujeres en primer año, según nivel y tipo de institución}

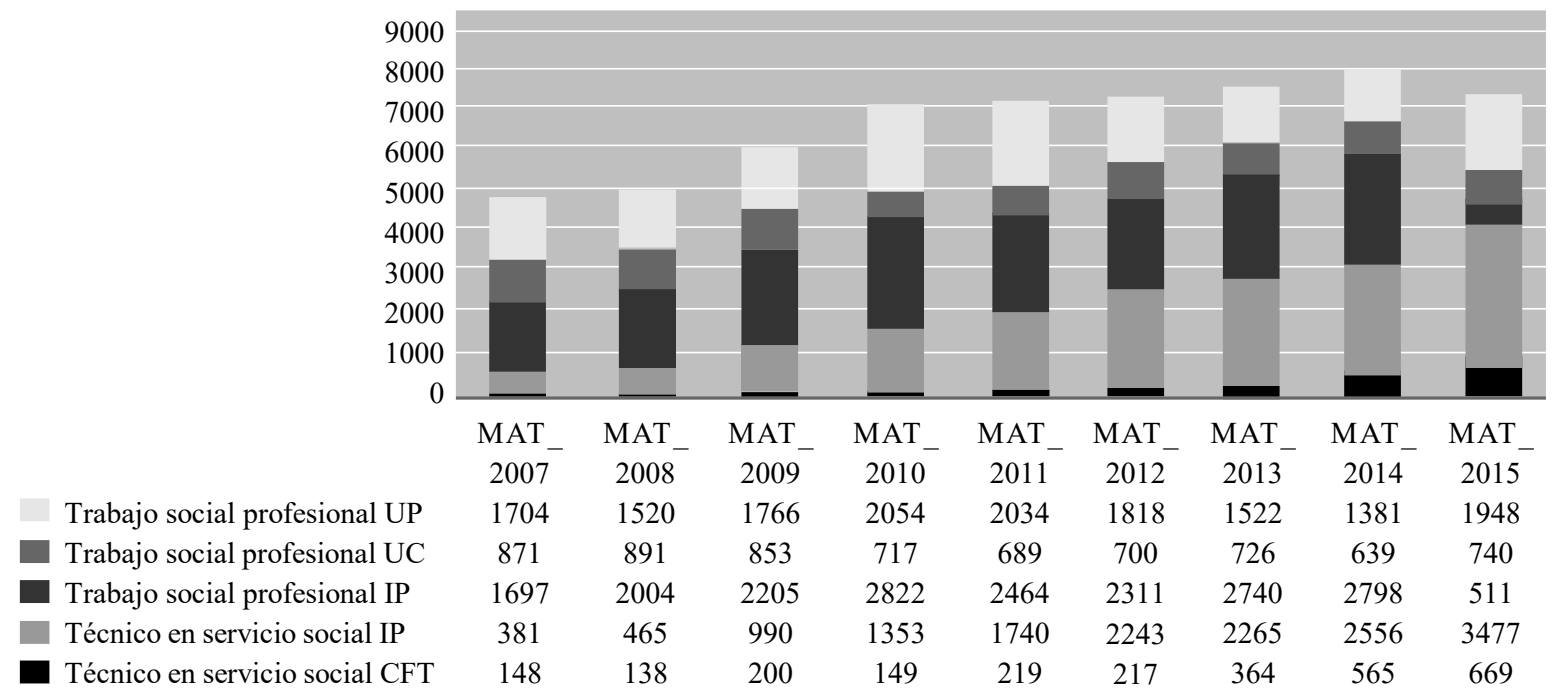

Se eliminó técnico en servicio social en UP, pues desde 2008 no hay ingresos.

Fuente: elaboración propia, con datos SIES(2016a). 
Se observa en el Gráfico 4 que el ingreso de mujeres a técnico en servicio social en IP, en términos absolutos, ha ido constantemente al alza, representando para 2015 la mayor matrícula de mujeres en primer año. Sin embargo, son los IP en el nivel de trabajo social quienes acumulan la mayor cantidad de alumnas de primer año a largo del periodo, con 19.552 estudiantes. Además, el mayor porcentaje acumulado en el particular, corresponde a técnico en servicio social en IP, con un $813 \%$ de aumento en su matrícula desde 2007 al 2015. Asimismo, y al igual que con los hombres, la matrícula acumulada de trabajo social profesional en IP y UC se expresa de manera negativa con un $-70 \%$ y un $-15 \%$, respectivamente.

\section{Tituladas y titulados}

Se han titulado 4.099 hombres y 23.119 mujeres, sumando un total de 27.218 personas desde 2007 al 2014. El aumento en términos absolutos más notorio, se produce en el año 2013, año en que las mujeres sobrepasan las 4.000 tituladas y los hombres los 700 titulados. La relación entre hombres titulados y mujeres tituladas, es de $15 \%$ de hombres y de un $85 \%$ de mujeres. La titulación de hombres aumentó en un $203 \%$, mientras que la titulación de mujeres aumentó en un $111 \%$, lo que en conjunto arroja una acumulación del 122\% de personas tituladas en trabajo social (técnico o profesional), en todas las instituciones de educación superior de Chile, desde 2007 al 2014.

La mayor cantidad de mujeres tituladas ocurre en trabajo social UP, con 7.041, seguido de trabajo social en IP, con 6.240 personas y de trabajo social en UC con 5.562. Sin embargo, la curva de crecimiento absoluto más notaria es el crecimiento en titulaciones de trabajo social en IP y de técnico en servicio social en IP (con 3.543 tituladas en desde 2007 al 2014). El nivel de técnico en servicio social en IP es el que representa el mayor aumento en temimos porcentuales $(772 \%)$, mientras que el menor aumento lo reflejan las tituladas en trabajo social de UC, con sólo un $22 \%$ de aumento en dicho periodo de tiempo (ver Gráfico 5).

\section{Gráfico 5 - Evolución de porcentaje de mujeres tituladas, por año, institución y nivel}

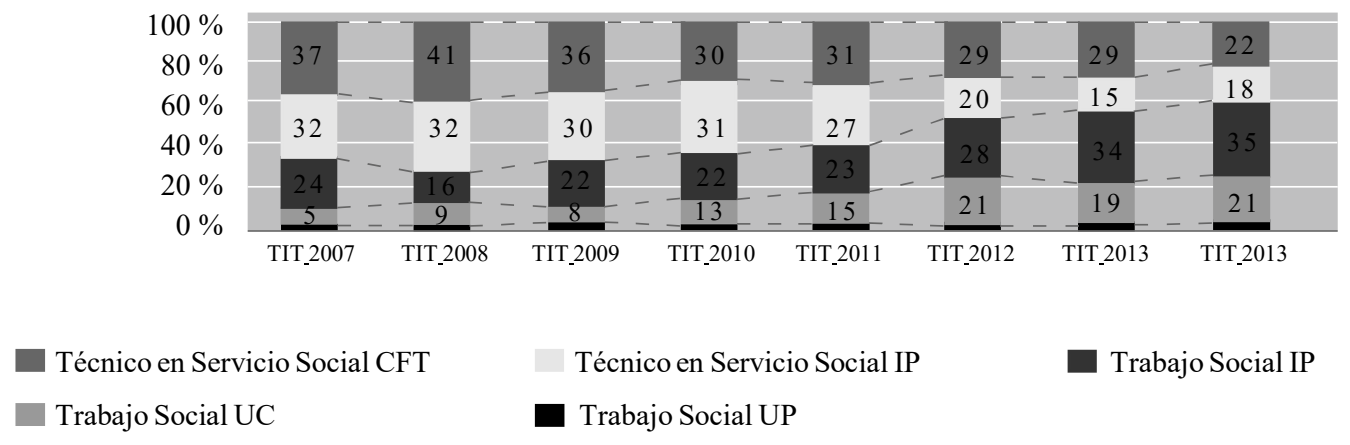

Fuente: elaboración propia, con datos SIES(2016b).

Respecto de los hombres titulados desde 2007 al 2014, el mayor aumento absoluto está dado por los titulados en trabajo social en IP. En el periodo analizado, se han titulado 4.099 hombres, de los cuales 1.194 lo han hecho en trabajo social IP, 1.114 en trabajo social UP, 1.016 en trabajo social UC y 774 en el nivel de técnico en servicio social (CFT más IP). La evolución absoluta en las titulaciones de hombres es similar a la enunciada para las mujeres. No obstante ello, es el nivel de técnico en servicio social en CFT el que ostenta la mayor alza porcentual, llegando a un $725 \%$ de aumento de titulados en 2014 (en comparación a 2007), seguido de técnico en servicio social de IP, con un 550\%. En general los titulados de trabajo social en todos los niveles y tipos de instituciones han tenido un alza de un 203\% (ver Gráfico 6). 


\section{Gráfico 6 - Evolución de porcentaje de hombres titulados, según nivel y tipo de institución}

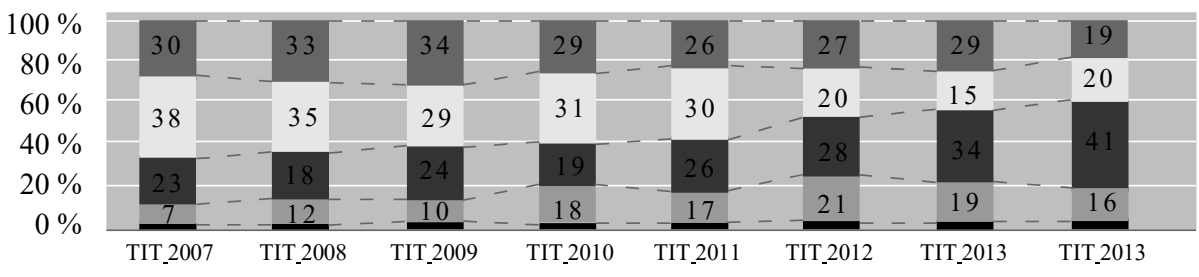

Técnico en Servicio Social CFT

Trabajo Social UC
Técnico en Servicio Social IP

Trabajo Social UP

Se eliminó a técnico en servicio social UP, ya que desde 2007 no hay titulaciones.

Fuente: elaboración propia, con datos SIES (2016b).

\section{Tasas de masculinización y feminización}

En el Gráfico 7 se observa que en el año 2007 de cada 1.000 matriculados en trabajo social, 119 mujeres y 16 hombres se titularon, mientras que en el año 2014 de cada 1.000 matriculados y matriculadas en trabajo social (técnico y profesional), 128 mujeres y 25 hombres se titularon. En términos brutos, las tasas de titulación de hombres y mujeres no varían sustancialmente, aunque entre los años 2009 y 2012 se observa una pequeña depresión en la tasa bruta de titulaciones mujeres. Asimismo, la media de crecimiento porcentual de la tasa bruta de titulación entre 2008 a 2014 , favorece a los hombres, con un $28 \%$ de crecimiento en su tasa de titulación versus un $-4 \%$ de variación en la tasa de titulación de mujeres, en el mismo periodo de tiempo .

\section{Gráfico 7 - Evolución de la tasa bruta de titulación, por sexo}

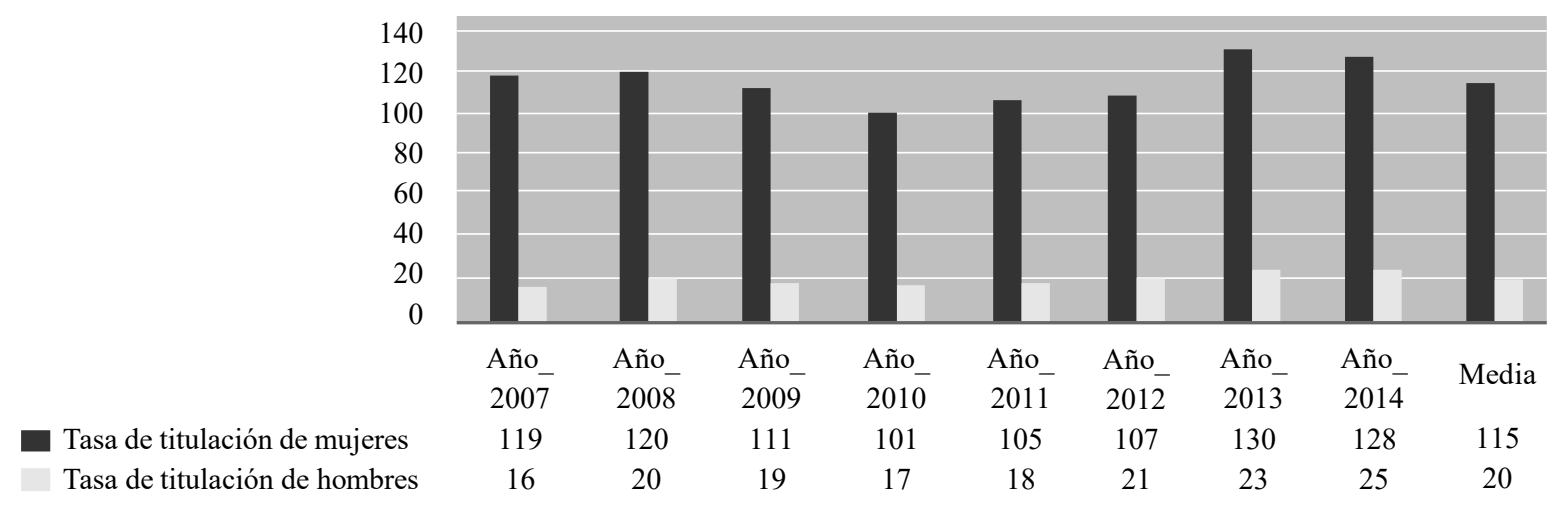

Fuente: elaboración propia, con datos SIES (2016b).

En el Gráfico 8 se observa la tasa de masculinización y feminización del trabajo social. Es decir, de la cantidad de estudiantes que ingresan a primeros años según sexo, por cada 1.000 estudiantes en todos los niveles y tipos de instituciones de educación superior. En términos brutos el número de hombres que ingresa a primer año está siendo cada vez menor en comparación a las mujeres. No obstante, la media de crecimiento porcentual de la tasa de masculinización en el periodo analizado fue de un $2 \%$ de aumento. Mientras que el promedio de la tasa de feminización fue de un $-8 \%$. 
Gráfico 8 - Evolución de la tasa bruta de masculinización y feminización

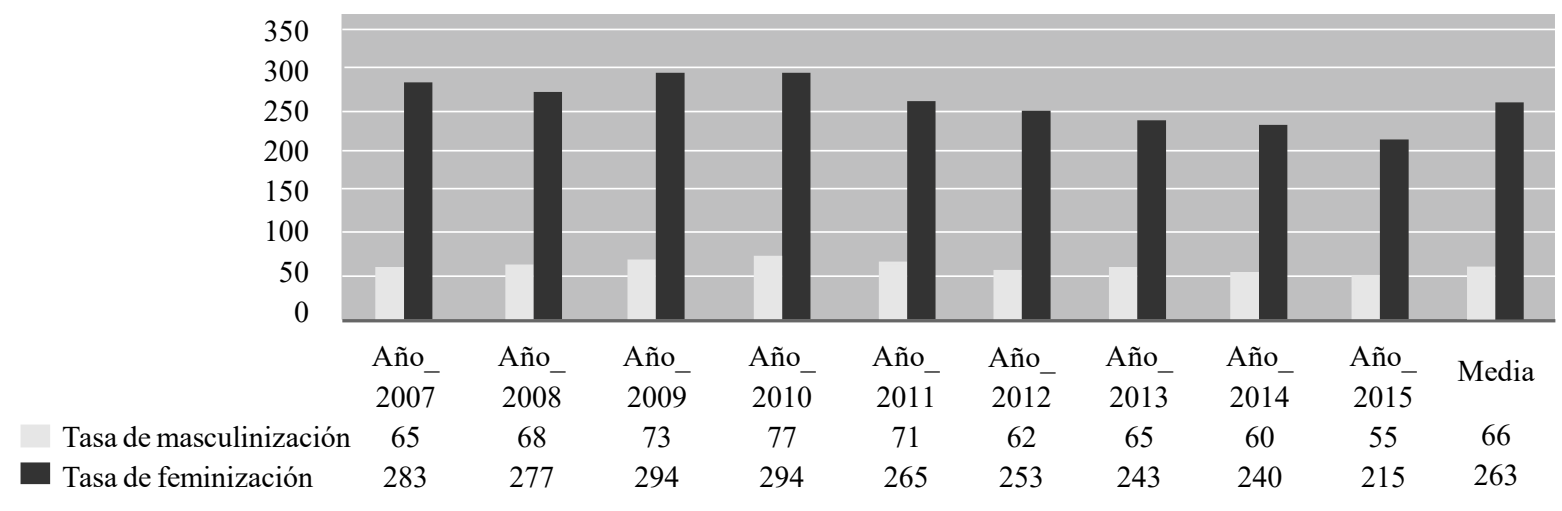

Fuente: elaboración propia, con datos SIES(2016a).

\section{Consideraciones finales}

Nueve años de evolución de la matrícula y la titulación en trabajo social se han analizado en las líneas precedentes, con acento en determinar las diferencias entre mujeres y hombres que deciden estudiar esta profesión y obtener una certificación en tal área. Desde el año 2007 al 2015 han estudiado trabajo social o técnico en servicio social 234.083 personas. El 81\% fueron mujeres y el 19\% fueron hombres. Tanto en hombres como en mujeres, la institución de educación superior y nivel de formación que concentra la mayor cantidad de matrículas son los institutos profesionales, ratificando los hallazgos de Saravia (2015), y la predominancia de la matrícula instipetizada del trabajo social (ASPEÉ, 2014, 2016), que la presente investigación indica que se sucede con independencia del sexo.

Se han titulado 4.099 hombres y 23.119 mujeres, sumando un total de 27.218 personas ( $15 \%$ de hombres y de un $85 \%$ de mujeres). El aumento de hombres titulados es mayor que las mujeres en el periodo analizado. Tanto en hombres como en mujeres, el porcentaje de titulaciones en profesionales UC y UP va perdiendo peso en contraposición al porcentaje de titulados en trabajo social y técnico en servicio de IP. A su vez, la variación porcentual de la tasa de titulación en el periodo analizado, favorece leventemente a los hombres. No obstante, la tasa de masculinización sigue siendo baja. Así, la gran diferencia en términos absolutos entre mujeres y hombres, hace poco probable que la proporción descrita de 1 hombre por cada 5,3 mujeres varíe en el corto y mediano plazo. Los datos indican que la disciplina y profesión del trabajo social seguirá siendo eminentemente estudiada y ejercida por mujeres, lo que reafirma los estudios de Bañez (1997), Castañeda y Salamé (2014), y Vidal (2009a, 2009b, 2009c). Asimismo, se instipetizará (ASPEÉ, 2014) en mayor medida, y según los datos, se tecnificaría tanto en hombres como en mujeres.

En consecuencia, el trabajo social fue, es, y seguirá siendo preferentemente ejercida y estudiada por mujeres. Ello obliga a cuestionarse si la aceptación de la ideología del amor (GRASSI, 1989) sigue teniendo un efecto selector en quienes ejercen el trabajo social, por sobre la capacidad crítica y racionalidad, lo que sumado a la tecnificación de la misma disciplina abran un flanco de críticas a la capacidad profesional de quienes se dedica al trabajo social profesional, con independencia del sexo. Ello, pues la concentración de mujeres en una profesión no debe tomarse como un derecho o un feudo de desarrollo profesional, sino que como el reflejo de inequidades de género, asociadas al cumplimiento de ciertos roles, vetando el ejercicio de otros. Así, y como diría Bourdieu (2005), la profesión del trabajo social apoya la maquinaria simbólica que ratifica la división sexual del trabajo. Metafóricamente hablando, se sucede un traspaso desde los quehaceres del hogar, a los quehaceres de la profesión.

Por otra parte, es importante cuestionarse si la preeminencia de mujeres en trabajo social es constitutiva de su origen o más bien es consecuencia de las condiciones laborales en la que se ejerce, ya que no es desconocido que la elección de programas de formación en los hombre está, entre otros aspectos, condicionada por las expectativas de ingresos monetarios futuros, más que por las actitudes o conocimientos a desarrollar dentro de una profesión o disciplina en particular (MALGWI; HOWE; BURNABY, 2005). En dicha elección, también es relevante las posibilidades de compatibilizar las responsabilidades laborales con las responsabilida- 
des familiares futuras, preocupación que está más presente en las mujeres que en hombres (MARKS; HOUSTON, 2002). Aunque este aspecto debe ser reducto de análisis de otra investigación.

\section{[...] la concentración de}

mujeres en una profesión no

debe tomarse como un

derecho o un feudo de

desarrollo profesional, sino

que como el reflejo de

inequidades de género,

asociadas al cumplimiento de

ciertos roles, vetando el

ejercicio de otros.

Adicional a los hallazgos principales, la investigación concluye que, con independencia del sexo, la profesión del trabajo social está y seguirá siendo ejercida y estudiada de forma instipetizada, privada y tecnificada. Esta preocupante situación, es un síntoma del estado de la educación superior en Chile y en el mundo, nivel educativo que se ha transformado en un mecanismo de transmisión de conocimientos acríticos, producto de la hegemonía del pensamiento neoliberal (CARMONA-LÓPEZ; TOROJARAMILLO; RIASCOS-GONZALES, 2014; OLIVA, 2008), que concibe a la educación superior como un instrumento de viabilidad del modelo, centrado en la preparación para el trabajo (OLSSEN; PETERS, 2005). Esto es especialmente sensible en trabajo social, ya que se lo atomiza en diferentes niveles de certificación artificiales, provocando problemas de identidad profesional, cuyas consecuencias inmediatas son la carencia de espacios laborales, mientras que sus consecuencias a largo plazo pueden implicar la desaparición de la disciplina del trabajo social en Chile.

De esta manera, y sólo con base a los datos descriptivos enunciados, es posible ahondar en la inquietud grassiana, especialmente cuestionándose el hecho de la creciente tecnificación de la formación en trabajo social, que convertiría al trabajo social en Chile en un dispositivo ejecutor de acciones de asistencia relacionadas al ámbito privado familiar, según lo entiende Touraine (2007). Es decir, alejándose de roles de trascendencia socio-políticos y concentrándose en aspectos micro-sociales de la vida cotidiana-privada, enfatizando la división social del trabajo establecida por Bourdieu (2005). Esta sentencia remoza lo enunciado por Iturrieta (2012), ya que el prestigio del trabajo social está condicionado en gran parte por su origen filantrópico, asociado a condicionantes de género que circunscriben al trabajo social como una semi-profesión, situación que estaría potenciada debido a la creciente tecnificación visualizada.

Por otra parte, y de manera especulativa, una mayor cantidad de estudiantes en educación superior, no minimiza las condicionantes de género de una profesión, al parecer las acentúa. Al menos así parece ocurrir en trabajo social, hipótesis que debe ser objeto de un nuevo estudio. En el mismo sentido, es necesario ahondar en la motivación de los hombres que estudian y ejercen el trabajo social, especialmente respecto de las funciones que se espera que cumplan en sus trabajos, profundizando los hallazgos de Valenzuela (2014), al incorporar el ejercicio laboral. Finalmente, y asociado a los hallazgos colaterales, es importante analizar los factores que motivan a hombres y a mujeres a preferir la formación entregada por institutos profesionales y/o centros de formación técnica, en desmedro de la formación universitaria en trabajo social. El desafío queda planteado.

\section{Referencias}

ASPEÉ, J. Análisis longitudinal de la exclusividad universitaria del Trabajo Social en Chile. Rumbos TS, Santiago, v. 11, n. 13, p. 10-32, 2016. Disponible en: <http://revistafacso.ucentral.cl/index.php/rumbos/article/view/291/266>. Acceso en: 13 jun. 2016. Trabajo social de mercado: Exclusividad universitaria ¿mito o realidad? Valparaíso: [s.n.], 2014.

BAÑEZ, T. Género y trabajo social. Acciones e Investigaciones Sociales, Zaragoza, n. 6, p. 151-188, 1997. Disponible en: <https:// papiro.unizar.es/ojs/index.php/ais/article/view/136/130>. Acceso en: 20 sept. 2016.

BOURDIEU, P. La dominación masculina revistada. Archipiélago: Cuadernos de crítica de la cultura, n. 67, p. 9-22, 2005.

CARMONA-LÓPEZ, R.; TORO-JARAMILLO, I.; RIASCOS-GONZALES, J. Caracterización de las instituciones de educación superior (IES) en Chile: Una aproximación a un modelo futuro de universidad. Revista Educación, San José (Costa Rica), v. 38, n. 2, p. 37-50, jul./dic. 2014.

CASTAÑEDA, P.; SALAMÉ, A. M. Perfil de las generaciones estudiantiles de trabajo social universitario periodo 2010 - 2014. Rumbos TS, Santiago, v. 9, n. 10, p. 79-88, 2014. Disponible en: <http://revistafacso.ucentral.cl/index.php/rumbos/article/view/102/ 98>. Acceso en: 5 mayo 2016. 
GRASSI, E. La mujer y la profesión de asistente social: el control de la vida cotidiana. Buenos Aires: Humanitas, 1989.

ITURRIETA, S. Sociología y trabajo social en el mercado laboral chileno: un análisis sociológico. Estudio comparativo para optar al grado de doctor en sociología. 2012. Tesis (Doctorado en Sociología en el Análisis de los Problemas Sociales en las Sociedades Avanzadas) - Universidad de Granada, Granada, 2012.

LUCI, F. La división sexual del trabajo de mando: carreras femeninas en las grandes firmas argentinas. Revista Katálysis, Florianópolis, v. 13, n. 1, p. 29-39, 2010.

MALGWI, C. A.; HOWE, M. A.; BURNABY, P. A. Influences on students' choice of college major. Journal of Education for Business, v. 80 , n. 5, p. $275-282,2005$.

MARKS, G.; HOUSTON, D. M. The determinants of young women's Intentions about education, career development and family life. Journal of Education and Work, v. 15, n. 3, p. 321-336, 2002.

OLIVA, M. A. Política Educativa y profundización de la desigualdad en Chile. Estudios Pedagógicos, Valdivia (Chile), v. 34, n. 2, p. 207226, 2008.

OLSSEN, M.; PETERS, M. A. Neoliberalism, higher education and the knowledge economy: from the free market to knowledge capitalism. Journal of Education Policy, London, v. 20, n. 3, p. 313-345, May 2005.

SARAVIA, F. A. La formación de los trabajadores sociales en Chile: ¿un asunto de oferta y demanda? Cuadernos de Trabajo Social, Madrid, v. 28, n. 1, p. 69-81, 2015. Disponible en: $<$ http://revistas.ucm.es/index.php/cuts/article/view/46510>. Acceso en: 10 jun. 2016.

SERVICIO DE INFORMACIÓN DE EDUCACIÓN SUPERIOR del Ministerio de Educación de Chile. Base matrícula histórica 2007-2015, actualizada al 26 agosto 2015. 2016a. Disponible en: <http://www.mifuturo.cl/index.php/bases-de-datos/matriculados>. Acceso en: 12 feb. 2016.

SERVICIO DE INFORMACIÓN DE EDUCACIÓN SUPERIOR del Ministerio de Educación de Chile. Base titulados histórica 20072014, actualizada al 26/08/2015. 2016b. Disponible en: <http://www.mifuturo.cl/index.php/bases-de-datos/titulados >. Acceso en: 12 feb. 2016.

TOURAINE, A. El mundo de las mujeres. Barcelona: Paidós Ibérica, 2007.

VALENZUELA, A. Masculinidades y estudiantes de trabajo social. Rumbos TS, Santiago, v. 9, n. 9, p. 37-44, 2014. Disponible en: $<$ http://revistafacso.ucentral.cl/index.php/rumbos/article/view/89/85>. Acceso en: 5 marzo 2016.

VIDAL, P. F. Aproximación a una caracterización del espacio socio-ocupacional del Trabajo Social en Chile. Colegio de trabajadores sociales de Chile, nov. 2009b. Disponible en: <http://www.trabajadoressociales.cl/provinstgo/documentos/ ESTUDIO\%20cARACTERIZACION\%20n.pdf>. Acceso en: 15 jun. 2016.

. Caracterización de las acciones del trabajo social. Cambios, continuidades y tensiones del Chile actual. Revista Venezolana de Trabajo Social, Maracaibo (Venezuela), n.6, p. 42-55, 2009c.

. Condiciones laborales de la profesión: ¿Precariedad laboral o conditio sine qua non? Emancipação, Ponta Grossa, v. 9, n. 1, p. 79-94. 2009a. .

\section{Notas}

1 Ver detalles en Aspeé (2014, 2016).

2 Para los autores, el trabajo social es indivisiblemente profesión y disciplina, por lo tanto incluye íntegramente título profesional y licenciatura. Por lo que la distinción mostrada de áreas de carrera genérica, se utilizó sólo con el propósito de que los hallazgos puedan ser replicados y como base de la discusión futura.

3 Servicio social y trabajo social son dos denominaciones de una misma profesión y disciplina, así se ha entendido consuetudinariamente y así lo ha ratificado la legislación chilena. Por consiguiente, los títulos profesionales de Asistente Social y de Trabajador social, son homónimos. Ver más en Aspeé (2014).

4 El Consejo de Rectores de las Universidades Chilenas (CRUCH), agrupa a 27 universidades chilenas estatales y privadas, con vocación pública, creadas antes de 1981, o derivadas de tales. Por su parte, las universidades privadas (UP), son totas aquellas que están fuera del CRUCH creadas luego de 1981.

5 La línea base la constituye el año 2007, y representa el 100\% sobre el cual se mide el avance de la tasa.

\section{Juan Elías Aspeé}

juan.elias.aspee@gmail.com

Doctorado en Políticas y Gestión Educativa por la Universidad de Playa Ancha (UPLA)

Docente agregado en la Escuela de Trabajo Social de la Pontifícia Universidad Católica de Valparaíso (PUCV) y Profesional en la Dirección de Relaciones Estudiantiles de la Universidad Técnica Federico Santa Maria (USM) 


\section{PUCV}

Escuela de Trabajo Social

Avenida Brasil, 2830

Valparaíso - Región de Valparaíso - Chile

\section{USM}

Dirección de Relaciones Estudiantiles

Avenida España, 1680

Valparaíso - Región de Valparaíso - Chile

\section{José Alejandro González Campos}

jgonzalez@upla.cl

Doctorado en Estadística por la Universidade Estadual de Campinas (UNICAMP)

Investigador y académico en Universidad de Playa Ancha (UPLA)

\section{UPLA}

Laboratorio Experimental de Saberes Matemáticos, Facultad de Ciencias Naturales y Exactas Avenida Leopoldo Carvallo, 270 - Playa Ancha

Valparaíso - Región de Valparaíso - Chile 